\title{
Model Based Wind Turbine Gearbox Fault Detection on SCADA Data
}

\author{
QIU Yingning ${ }^{*}$, SUN Juan ${ }^{1}$, CAO Mengnan ${ }^{1}$, WANG Hao $^{1}$, FENG Yanhui ${ }^{1}$, YANG Wenxian ${ }^{2}$, \\ INFIELD David
}

\author{
${ }^{1}$ School of Energy and Power Engineering, Nanjing University of Science and Technology, China, \\ Email:yingningqiu@yahoo.com,yingning.qiu@njust.edu.cn;sunjuan54321@aliyun.com \\ ${ }^{2}$ School of Marine Science and Technology, Newcastle University, UK \\ ${ }^{3}$ Department of Electronic and Electrical Engineering, Strathclyde University, UK
}

Keywords: WT gearbox, SCADA, lubrication system, fault detection.

\begin{abstract}
Developing effective wind turbine fault detection algorithm is not only meaningful for improving wind turbine reliability but also crucial for future intelligent wind farm operation and management. Typical wind turbine gearbox condition monitoring is based on vibration signals, which is effective to detect failures with high frequency signal range. But it may not be effective on low speed components which have low frequency signal characteristic of different failure modes. SCADA system collecting multiple low frequency signals provides a cost-effective way to monitor wind turbines health and performance, while its capability on fault detection is still an open issue. To systematic understand wind turbine systems, this paper presents research results of model based wind turbine gearbox fault detection. Through a detail analysis of thermodynamic process of gearbox lubrication system, a wind turbine drive train model which considers heat transferring mechanism in gearbox lubrication system is built to derive robust relationships between transmission efficiency, temperature, and rotational speed signals of wind turbine gearbox and suggest useful information for lubrication system design and optimization. The result obtained in this work is useful for wind turbine gearbox design and effective algorithm development of fault detection.
\end{abstract}

\section{Introduction}

With the increasing electricity generation capacity of wind turbine, gearbox sizes dramatically increase. Wind farms are being explored from onshore to offshore, which drives the operational costs to rise significantly. The relatively frequent occurrence of WT gearbox failures is particularly critical since field service is expensive and time-consuming. On the other hand, long downtime which is due to gearbox malfunction will lead to incalculable economic losses [1]. Therefore, gearbox health monitoring is necessary for wind turbine. Developing effective wind turbine fault detection algorithm is not only meaningful for improving wind turbine (WT) reliability but also crucial for future intelligent wind farm operation and management.
Due to the variable-speed nature of wind turbines operation characteristic, there is challenge on using classical method to develop fault detection algorithm. Typical wind turbine gearbox condition monitoring is based on vibration signals, which is effective to detect failures with high frequency signal characteristic. But it may not be effective on low speed components which have low frequency signal characteristic for different failure modes. In addition, SCADA system collecting multiple low frequency signals may provide a costeffective way to monitor wind turbines health and performance although its capability on fault detection is still an open issue. Recent researches put efforts on SCADA data to develop fault detection algorithm [2]. For example, artificial intelligent or state estimate methods are tried [1]. Although they are pioneer works to prove the feasibility of using SCADA data for fault detection, these methods rely on relatively large data volume for model training and these methods may not be able to identify different failure modes. Therefore, a systematic understanding of wind turbine systems will be important to help identify fault symptom by reflecting failure mechanism.

This paper presents research results of model based wind turbine gearbox fault detection, which systematically uncover gearbox failure characteristics. Firstly, based on energy transmission mechanism analysis wind turbine drive train models are developed and embedded into wind turbine system model; secondly, thermodynamic process of gearbox lubrication system is studied and the energy loss model which relates the gearbox transmission efficiency to oil temperature variation is derived; finally, by introducing fault to the drive train the failure characteristics are obtained by comparing the signal variation pattern between healthy and faulty circumstances. This paper presents a model based process to derive robust relationships between transmission efficiency, temperature, rotational speed and WT output power. The result obtained suggests useful information for gearbox lubrication system design and optimization. It is also useful for wind turbine gearbox design and effective algorithm development of fault detection.

\section{Gearbox Lubrication System Cooling Process Analysis}




\subsection{Gearbox Lubrication System Structure}

Wind turbine gearbox lubrication system not only reduce transmission power losses by decreasing friction between the drive gears but also improve gear transmission efficiency through its cooling effect [3]. Therefore, lubrication system is an indispensable part of WT gearbox. The schematic of WT gearbox lubrication system is illustrated as figure 1 .

It mainly consists of following components:

1) Oil pump unit

Major components of oil pump unit include motor, pump and filters. Internal filters include coarse filter and fine filter. Pressure sensors are set at the filters' head and tail which are used to monitor the status of the filters.

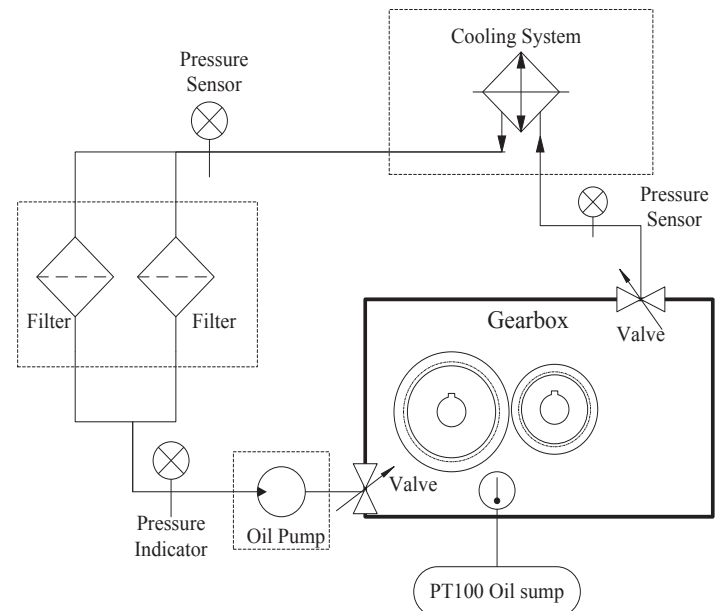

Figure 1.Schematic of WT gearbox lubrication system.

2) Heat exchange unit

Heating and cooling devices are main components within heat exchange unit. Before the devices start, lubrication oil needs to be heated to higher than $-15{ }^{\circ} \mathrm{C}$ when the oil temperature is below $-15{ }^{\circ} \mathrm{C}$. During gearbox operational process, when lubrication oil temperature is higher than $60{ }^{\circ} \mathrm{C}$, air-cooling or forced water cooling system of gearbox lubrication system are triggered in order to keep the whole gearbox system being in an optimal working status.

3) Oil filter unit

Oil filters are used to filter impurities or metal particles within the lubrication oil in order to maintain oil quality and to prevent further wear and tear of gearbox mechanical components. Under normal circumstances, the oil flow into the outer chamber through the filter inlet and export from internal chamber outlet after filtration.

\subsection{Power Loss Mechanism of a WT Gearbox}

In a WT gearbox, there are several energy dissipation processes. Understanding these mechanisms is extremely important to evaluate the power loss and the efficiency of a gearbox [4]. The power losses that have significant influence on gearbox performance include [5][6]:

- Load dependent losses - accounts for the tooth friction power losses due to the sliding between gear teeth and the friction between rolling bearing elements.
- No-load dependent losses or churning power losses referred to the viscous friction between all mechanical elements and the fluid where they are immersed.

- Mass and inertia of the components of the drive train which has not been considered in this paper.

The thermal equilibrium of gearbox system is reached when the power losses inside the gearbox housing are equal to the heat flow dissipated from gearbox, which can be described by the equation below:

$$
P_{f r}+P_{s l}+P_{s p l}+P_{M_{0}}+P_{M_{1}}=P_{\text {total }}
$$

Where $\mathrm{P}_{\mathrm{fr}}$ is the friction power dissipated by gears, $\mathrm{P}_{\mathrm{M} 1}$ is the friction power dissipated by the bearings, $\mathrm{P}_{\text {spl }}$ is the churning power dissipated by the gears, $\mathrm{P}_{\mathrm{M} 0}$ is the churning power dissipated by the bearings and $\mathrm{P}_{\mathrm{sl}}$ is the churning power dissipated by the seals.

\subsection{Power Losses Impact on Gearbox Oil Temperature}

WT gearbox oil temperature will become stable when the power losses in the gearbox and its heat dissipation reach equilibrium. Whenever wind turbine or its lubrication system malfunction which leads to increase of power losses or reduction of heat dissipation, the oil temperature will increase. Assuming the heat generated by the WT gearbox is uniform during its operation process, it is equal to the sum of heat dissipated and stored in the gearbox. Figure 2 shows the WT gearbox heat dissipation path.

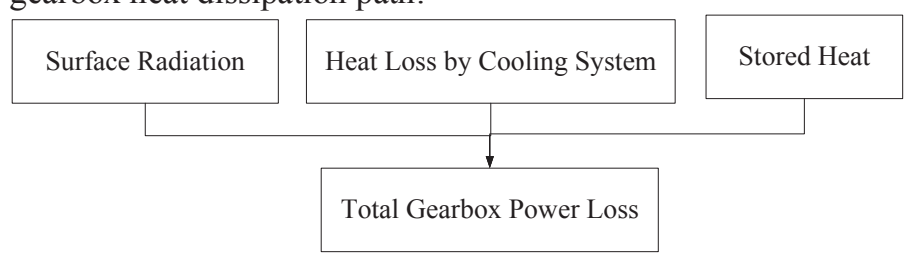

Figure2. Schematic of WT gearbox heat dissipation path.

Accordingly, heat is dissipated through three channels - heat conduction, heat convection and thermal radiation [7]. In fact, the influence of thermal radiation is small enough to be neglected. Therefore, the total heat dissipation in the gearbox includes [3]:

- heat convection and conduction to the surrounding environment through the gearbox surface, which is represented by $\mathrm{P}_{1}$;

- heat exchange by oil supplying from outside by pipeline in injection manner and going through cooling system, which is represented by $\mathrm{P}_{2}$;

- heat being passed to the adjacent components through the coupling shaft and base, represented by $\mathrm{P}_{3}$.

Assuming the gearbox input power is $\mathrm{P}$, its transmission efficiency is $\eta, \mathrm{P}_{\text {total }}, \mathrm{P}_{1}, \mathrm{P}_{2}, \mathrm{P}_{3}$ can be expressed as follow:

$$
\begin{aligned}
& P(1-\eta)=P_{\text {total }} \\
& P_{1}=\alpha_{G} A\left(T_{G}-T_{a m b}\right) \\
& P_{2}=c \rho Q_{\varepsilon}\left(T_{G}-T_{0}\right) \\
& P_{3}=c M\left(T_{G}-T_{a m b}\right) / t
\end{aligned}
$$


$\alpha_{\mathrm{G}}$ is the gearbox shell heat transfer coefficient, $\mathrm{W} /\left(\mathrm{m}^{2} \cdot \mathrm{K}\right)$. For unhindered still air convection, its outline is $15 \sim 25$. A is the surface area of the cabinet, $\mathrm{m}^{2}$. The enclosure length is set as $3225 \mathrm{~mm}$, height is $1000 \mathrm{~mm}$, width is $1400 \mathrm{~mm}$ in this paper. So the heat radiation area is $13.765 . \mathrm{T}_{\mathrm{G}}$ is lubrication oil temperature, $\mathrm{K}$. $\mathrm{T}_{\mathrm{amb}}$ represents ambient temperature, $\mathrm{K}$. c is the specific heat capacity of the cooling medium, $\mathrm{J} /(\mathrm{kg} \cdot$ $\mathrm{K}$ ), which is generally taken to be 2000. $\rho$ is the density of oil, $\mathrm{kg} / \mathrm{m}^{3}$, which is taken as $900 . \mathrm{Q}_{\varepsilon}$ represents the flow of the loop injection, $\mathrm{m}^{3} / \mathrm{s}$, which is estimated to be $1.05 \times 10^{-3} . \mathrm{T}_{0}$ is the lowest lubrication and cooling system open temperature, $\mathrm{K}$, which is set as $50{ }^{\circ} \mathrm{C}$.

\section{Simulation Model and SCADA System}

\subsection{Simulation Model}

Typically, wind turbine simulation assumes that the system is in healthy state. It is to assume that the power is transmitted through the main shaft, gearbox and generator with certain efficiency ( $\mathrm{y})$. The control system is also designed assuming the drive train of WT is under healthy condition [8]. It is illustrated as the upper part of figure 3 . In realistic situation, a failed gearbox inevitably caused the degradation of power transmission efficiency due to increase of friction losses, churning losses or rolling losses. The increased energy loss will be ultimately dissipated through gearbox housing surface or be taken away by the cooling system. The lower part of figure 3 illustrates this process. A dynamic model of WT with $1-2 \mathrm{MW}$ which considers energy loss by gearbox and reflect heat dissipation path is established.

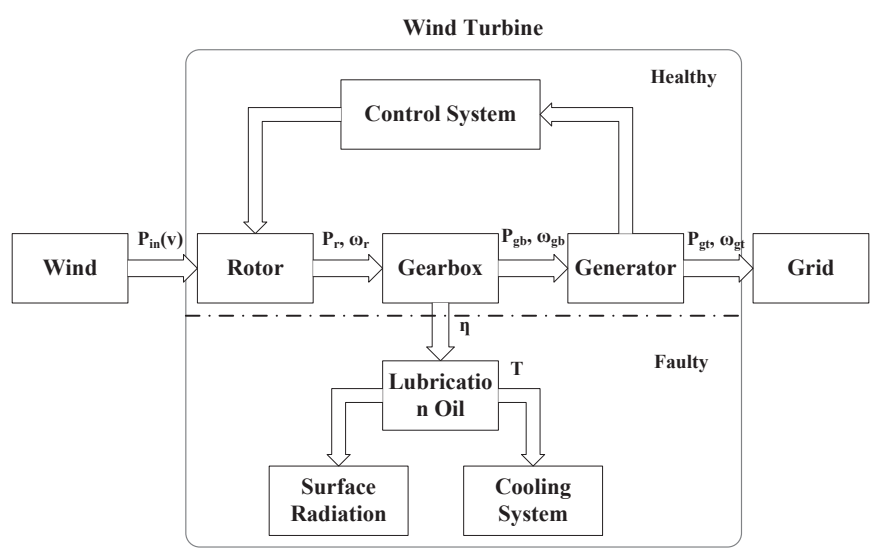

Figure3. Mechanism of WT gearbox and subsystems

Energy transmission efficiency of a gearbox is a function of the energy being transmitted [9]. It rises from low to high with the increase of transmitted energy. Therefore, wind turbine gearbox efficiency is rising from low wind speed to the rated wind speed. In this paper, two transmission efficiency curves of a gearbox are assumed. It is shown in figure 4. One is in the range between $66 \%$ and $97.5 \%$ and the other is between $62.5 \%$ and $96.5 \%$. They are used to simulate a wind turbine with degraded gearbox performance.

\subsection{SCADA Data Explaination}

WT Supervisory Control and Data Acquisition (SCADA) system archives comprehensive signal information. It is installed in a WT in order to monitor individual turbine performance as its initial purpose. The data used in this paper is taken from a WT with size 1-2MW. The WT output power, wind speed, WT rotational speed, gearbox rotational speed and its lubrication system oil temperatures are measured and averaged within 10 minutes [10]. To properly choose related performance data, mechanism analysis as described in the previous section is needed. In addition, noisy data should be filtered and processed. The data used are divided into different time ranges in order to present their variation tendency. Every three months data is grouped together and 9 months data are divided into 3 sections accordingly. They are compared with simulation model result.

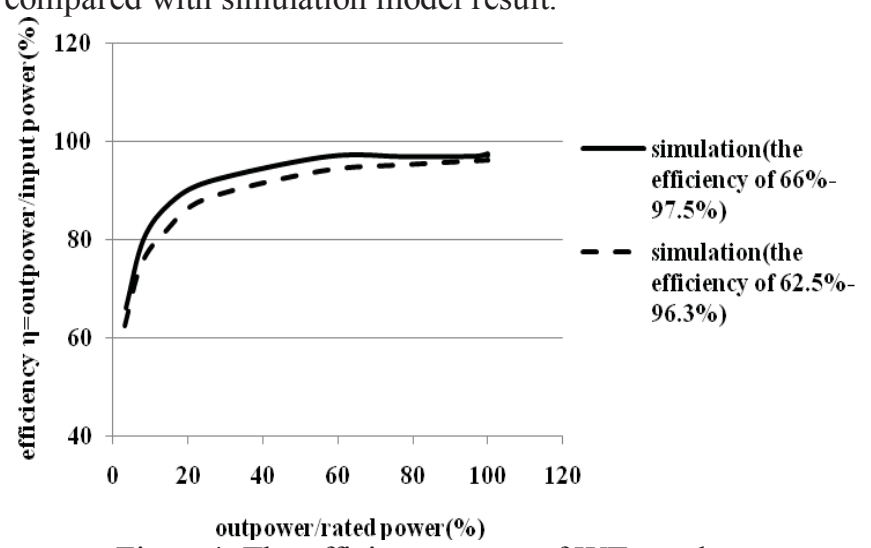

Figure4. The efficiency curve of WT gearbox.

\section{Results and Discussions}

\section{(1) Power Curve}

The power curve of simulated and SCADA data are compared under different wind speeds' range and they are shown in figure 5. The solid line is simulated curve and the scatter points are the averaged power values for every three months periods at different wind speeds. It was shown that with the degradation of gearbox efficiency output power slightly decreases. However, the variation in the power curve is not obvious. The slight power disagreement at the beginning of rated wind speed area may be due to the difference of control strategic configuration at this area.

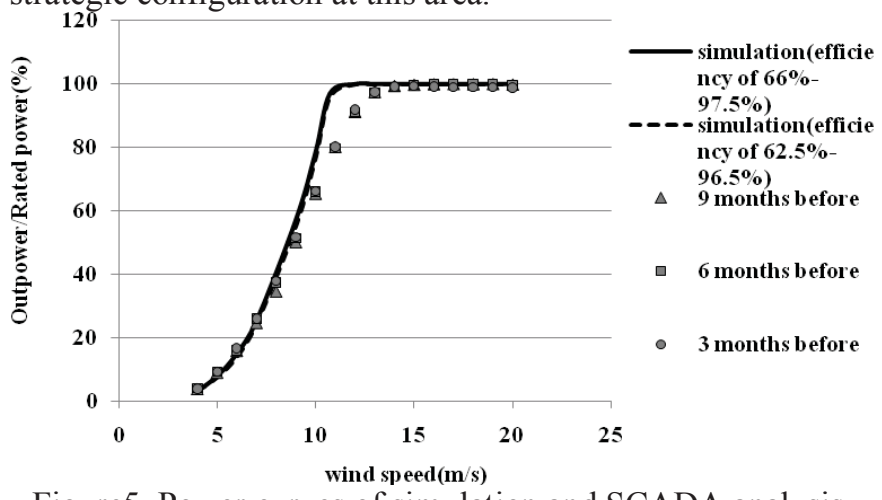

Figure5. Power curves of simulation and SCADA analysis. 
(2) Oil Temperature

According to Eq.(2)-(5) and WT systematic simulation procedure as illustrated in figure 3 , gearbox oil temperature rise which is the absolute oil temperature get rid of ambient temperature effects is obtained. The simulated and SCADA data results are compared in figure 6. It was shown that good agreement between simulated results and $6 \& 3$ months period before failure. This sufficiently proves the simulation model and cooling mechanism of the lubrication system described. The degradation of transmission efficiency of gearbox is the main reason for the temperature rise observed in the lubrication oil. The turning power point observed in 6 months period at wind speed of $7 \sim 9 \mathrm{~m} / \mathrm{s}$ is because of the start of the cooling system where the temperature of the oil is above 60 degree. The start of the cooling system results in reduction of oil temperature rise. We also observed some sudden temperature rise drop at wind speed of $19 \mathrm{~m} / \mathrm{s}$ on 9 months period. This is due to not enough data sample during that period and at that specific wind speed does not affect the overall characteristics.

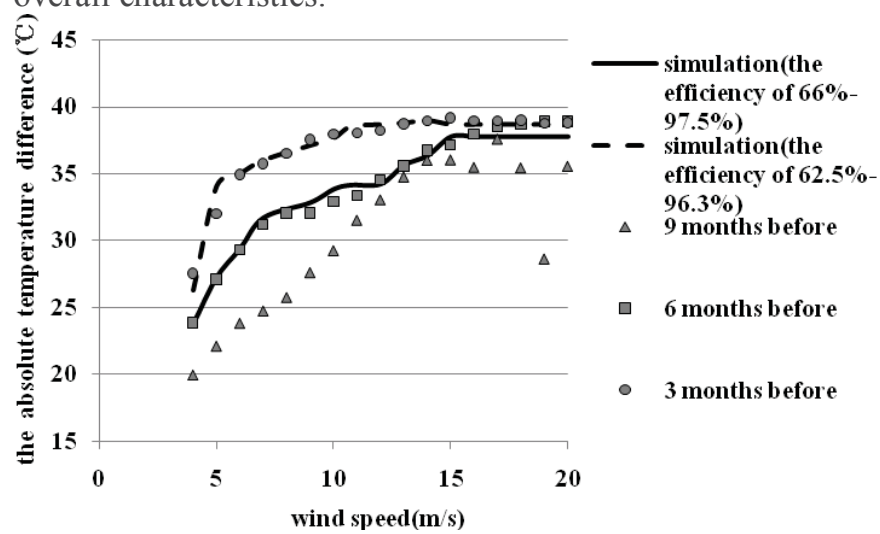

Figure6. Absolute oil temperature with decreased gearbox efficiency

\section{(3) Output Power Influence}

Gearbox oil temperature rise versus the ratio of WT output power normalized to rated power are compared in figure 7. It shows that under the situations of degraded gearbox transmission efficiency, higher temperature rise are clearly observed. The temperature rise grows with the increase of WT output power. The simulation result obtained here by setting the same ambient temperature. The disagreement here may due to the difference of ambient temperature during the 3 months period. Next subsection will investigate ambient temperature effect.

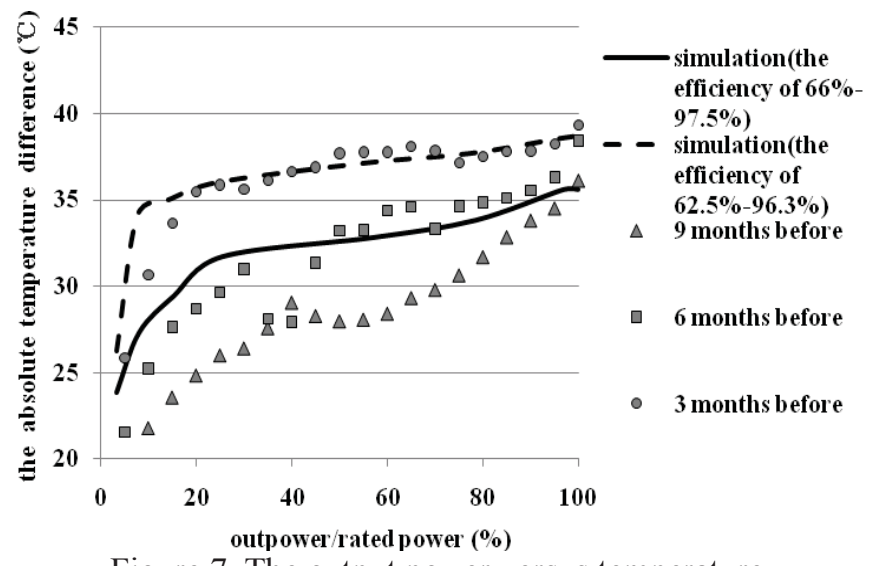

Figure 7. The output power versus temperature.

\section{(4) Ambient Temperature Influence}

Figure 8 shows that at the wind speed of $10 \mathrm{~m} / \mathrm{s}$ which is below the rated wind speed, the oil temperature rise linearly decreases with the increase of ambient temperature which varies between $10^{\circ} \mathrm{C}$ to $40^{\circ} \mathrm{C}$. With the time period approaching failure, this linear relationship between oil temperature rise and ambient temperature does not change except the whole line shift higher, which indicates the higher temperature rise of the oil.

\section{Conclusion}

A model of variable-speed WT wind turbine which is 1-2MW and considered gearbox lubrication subsystem is established in this paper. The validation of the model is proved by comparing the results of simulation and SCADA data. This sufficiently proves the thermal dynamics mechanism within gearbox and the heat transfer principle of lubrication system. The result shows the oil temperature rise is due to the degradation of gearbox transmission efficiency while its magnitude is jointly determined by the power transmitted and the ambient temperature. The nonlinear relationship between oil temperature rises with wind speed/ output power is due to the efficiency nonlinearity. But the oil temperature rise exhibits linear relationship to ambient temperature. These characteristics can be used to develop effective fault detection algorithm for WT. And the mechanism proved in this paper can be used for lubrication and cooling systems design.

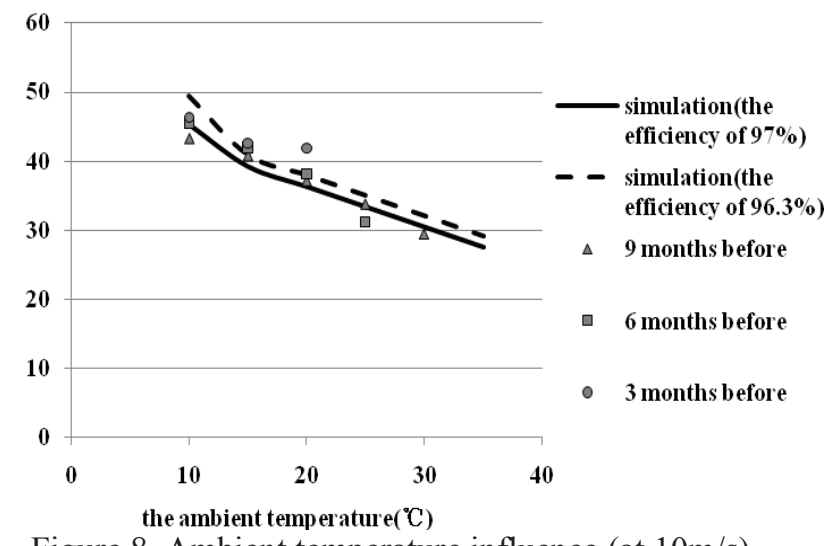

Figure 8. Ambient temperature influence (at $10 \mathrm{~m} / \mathrm{s}$ ). 


\section{Acknowledgement}

This is a research work funded by The Natural Science Foundation of Jiangsu Province (BK2013135), Start-up Scientific Research Project of NUST, Jiangsu Top Six Talent Summit Fund (ZBZZ-045).

\section{References}

[1] A.Zaher,S.D.J.McArthur,D.G.Infield. Online Wind Turbine Fault Detection Through Automated SCADA Data Analysis. Wind Energy.2009;12:574593;DOI:10.1002/we.319.

[2] Yanhui Feng,Yingning Qiu,Peter J Tavner. Monitoring Wind Turbine Gearbox. Wind Energy 2012;DOI:10.1002/we.1521.

[3] Niemann G. ,Winter H. Maschinenelemente. Springer,2003.

[4] Ramiro C.Martins, David E.P.Goncalves, et al.Torque loss in a gearbox lubricated with wind turbine gear oils.Lubrication Science,2013;25:297-311.

[5] Changenet C, Velex P. A model for the prediction of churning losses in geared transmissions - preliminary results. Journal of Mechanical Design, 2007; 129(1):128-133.

[6] Höhn B-R, Michaelis K. Influence of oil temperature on gear failure. Tribology International 2004(37):103-109.

[7] Tao Wenquan. Heat Transfer. Higher Education Press, 2008.

[8] Qiu Yingning,Sun Juan,Feng Yanhui. Wind Turbine Fault Simulation. Renewable Power Generation Conference (RPG), $2^{\text {nd }} I E T$, Sept.9-11,2013,Beijing.

[9] ErichHau.WindTurbine:Fundametals,Technologies,Appl ication,Economics. Springer, 2008.

[10] Yanhui Feng, Yingning Qiu,Peter J Tavner. Use Of SCADA And CMS Signals For Failure Detection And Diagnosis Of A Wind Turbine Gearbox. EWEA 2011,Brussels. 